\title{
1986 MRS Spring Meeting Preview
}

The third annual MRS Spring Meeting will be held in Palo Alto, California, April 15-18, 1986 featuring 9 topical symposia, 16 short courses held throughout the week, a job placement center, and the popular Symposium X, Frontiers of Materials Research. Program Chairs Wei-Kan Chu, Rod Quinn, and Malcolm Thompson report that the technical program contains an extensive overview of many important new materials developments. The following is a description of activities planned for the week. Attendees are encouraged to register in advance using the registration form in this issue.

\section{Registration Fees}

Preregistration fees (those received by March 20, 1986) are:

Regular

MRS member: $\$ 125$

Nonmember: $\$ 155$

Student

MRS student member: $\$ 30$

Student nonmember: $\$ 45$

At-meeting fees (those received after March 20, 1986) are:

Regular

MRS member: $\$ 140$

Nonmember: $\$ 170$

Student

MRS student member: $\$ 40$

Student nonmember: $\$ 55$

Payment of the registration fee entitles the participant to attend all symposia, as well as the Plenary and Student Awards Session and the reception that follows.

\section{Job Placement Center}

A job placement service will be available to attendees of the Spring Meeting. The purpose of the Center is to arrange interviews between prospective employees and employers attending the meeting. Candidate forms will be available for examination by interested employers. Descriptions of employment opportunities offered by employers will not be available before the meeting since there is no compulsory registration for employers.

Individuals who wish to participate should complete an employment candidate form available in this BULLETIN. Individuals should also bring resumes to the Placement Center. There will be a $\$ 5.00$ fee for use of the Placement Center. Individuals who have preregistered for the Center should report to the Center at the Hyatt Rickeys Hotel to receive a placement identification number. To register on-site, candidates should report to the Center to complete a candidate form.
Return completed forms by March 14, 1986 to Beverly Citrynell, Manpower Placement Division, American Institute of Physics, 335 East 45 th Street, New York, NY 10017

\section{Plenary Address}

Dr. Pieter Meyers, Director of the Conservation Center, Los Angeles County Museum of Art, will present a keynote lecture entitled "Materials Studies in the Examination of Works of Art."

Micro-characterization of materials, the development of new materials and studies of materials interactions have led to remarkable advances in the study and conservation of works of art, both ancient and contemporary. Such advances will be illustrated graphically with special reference to several intriguing recent case histories.

Dr. Meyers earned his PhD in nuclear chemistry and nuclear physics at the University of Amsterdam. He subsequently undertook research at Brookhaven National Laboratory, applying nuclear techniques to the study of archeological materials. He developed a new research laboratory at New York's prestigious Metropolitan Museum of Art from 1970 until accepting the responsibilities for Conservation Research at the Los Angeles County Museum of Art in 1981. His experience ranges over many fields and he is a leader in conservation research today.

Prior to Dr. Meyers' lecture, new MRS Sections and Student Chapters will be presented with their charters, and winners of Graduate Student Awards will be recognized.

\section{Heteroepitaxy on Si Technology} (Symposium A)

Wednesday-Friday, April 16-18

Chairs: J.C.C. Fan, MIT Lincoln Laboratory; J. M. Poate, AT\&T Bell Laboratories.

Approximately 27 papers will cover growth of $\mathrm{GaAs}$ on $\mathrm{Si}$, properties of $\mathrm{GaAs}$ on $\mathrm{Si}$, heterostructures of semiconductors and insulators on $\mathrm{Si}$, device properties of $\mathrm{GaAs}$ on $\mathrm{Si}$, heterostructures of semiconductors and metals on $\mathrm{Si}$. Invited speakers include: H. Kroemer, S. Sakai, M. Akiyama, Y. Ohmachi, H. Ishiwara, H. Morkoc, T.H. Windhorn, T.R. Tung, and K.L. Wang. A panel discussion will explore the future of $\mathrm{GaAs}$ on $\mathrm{Si}$.

Compound Semiconductor Conductors (Symposium B)

Tuesday-Friday, April 15-18
Chairs: L. Ralph Dawson, Sandia National Laboratories; Vassilis Keramidas, Bell Communications Research.

Approximately 39 papers will span bulk and surface processes, molecular beam epitaxy, characterization, metal-semiconductor interfaces/silicon carbide, and II-VI materials. Invited speakers include: R.N. Thomas, M.B. Panish, H.M. Cox, J.F. Schetzina, A.S. Jordan, P.I. Cohen, and D. Collins.

\section{Plasma Processing (Symposium C)}

Tuesday-Friday, April 15-18

Chairs: J. Coburn, AT\&T Bell Laboratories: D.W. Hess, University of CaliforniaBerkeley.

Approximately 68 papers will discuss current developments in plasma processing, diagnostics, metastable materials, modeling, deposition, radiation effects, and ion-surface chemistry. Invited speakers include: K. Herb, C.I. Tracy, M. Isaacson, V.M. Donnelly, A. Garscadden, J.A. Reimer, B.S. Meyerson, D.B. Graves, J. Keller, M.J. Kushner, G. Lucovsky, G.S. Oehrlein, L.C. Feldman, J.M. Mayer, and R. Walkup.

\section{Materials Characterization}

(Symposium D)

\section{Tuesday-Thursday, April 15-17}

Chairs: Marc-A. Nicolet, California Institute of Technology and Nathan W. Cheung, University of California-Berkeley

Approximately 70 oral and poster papers will cover TEM, SEM, ion channeling, RBS, SIMS, Auger spectroscopy, laser microprobe mass analysis, hyperfine interactions, Raman spectroscopy, magnetic resonances and other methods for analysis of metals, alloys, and semiconductor devices. Invited speakers include: C.R. Helms, R. Gronsky, P.E. Russell, W.K. Chu, C. Evans, Jr., R.J. Nemanich, B.M. Paine, R.W. Hoffmann, N. Amer, P.S. Alexopoulos, E. Weber, F. Ponce, R.L. Kubena, N.M. Johnson, and A. Rosencwaig.

\section{Materials Issues in Amorphous Semiconductor Technology (Symposium E)}

Tuesday-Friday. April 15-18

Chairs: D. Adler, Massachusetts Institute of Technology; Y. Hamakawa, Osaka University; and A. Madan, Glasstech Solar, Inc.

Approximately 110 oral and poster presentaContinued 
Continued from previous page

tions will explore growth and electronic properties of amorphous silicon films; preparation and characterization of amorphous silicon films; amorphous silicon and chalcogenides; amorphous silicon alloys; chemical vapor deposition of amorphous silicon films; chalcogenides; contacts and interfaces; photoreceptors and image sensors; devices, interfaces, and superlattices; solar cells; thin-film transistors. Invited speakers include: A. Gallagher, J.D. Joannopoulos, J.D. Cohen, K. Tanaka, M. Aiga, M. Konagai, C.C. Tsai, M. Hirose, Y. Kuwano, D.E. Carlson, Y. Tawada, Y. Uchida, M.J. Thompson, and Z. Yaniv.

Materials Issues in Silicon Integrated Circuit Processing (Symposium F)

Tuesday-Friday, April 15-18

Chairs: M. Wittmer, International Business Machines; J. Stimmell, National Semiconductor; and M. Strathman, Charles Evans \& Associates.

Approximately 79 papers will explore silicon materials science, epitaxy, ion implantation, contact and interconnect materials, high pressure oxidation, rapid thermal processing, and dielectrics. Invited speakers include: G.A. Rozgonyi, T.E. Seidel, T.J. Magee, H. Melchior, J.M. Phillips, S.T. Pantelides, N. Cheung, R.A. Levy, H.U. Schreiber, T.I. Kamins, M.O. Aboelfotoh, S.P. Tay, and M. Current.

Electronic Packaging Materials Science

(Symposium G)

Tuesday-Thursday, April 15-17

Chairs: D.R. Ulrich, Air Force Office of Scientific Research; R.C. Pohanka, Office of Naval Research; D.R. Uhlmann, Massachusetts Institute of Technology; and K.A. Jackson, AT\&T Bell Laboratories.

Approximately 39 papers will cover processing, mechanical properties and reliability, polymers, interfaces and films. Invited speakers include: L.E. Cross, B.G. Bagley, T.L. Baker, A. Evans, K.M. Prewo, T-W. Chou, M.R. Pinnel, and C-A. Chang.

Better Ceramics Through Chemistry

(Symposium H)

Tuesday-Friday, April 15-18

Chairs: C. Jeffrey Brinker, Sandia National Laboratories; David E. Clark, University of Florida; and Donald R. Ulrich, Air Force Office of Scientific Research.

Approximately 111 oral and poster presentations will report on solution chemistry and synthesis-gels and powders, characterization of chemically derived ceramics, drying and consolidation, structure of random and ordered systems, nonoxides, comparison of chemically and conventionally derived ceramics, application of MO/MD calculations, materials for electronic pack-

Continued

\section{SPRING MEETING TIMETABLE}

\section{REGISTRATION (Hyatt Rickeys Hotel)}

Monday, April 14:4:00 p.m.-9:00 p.m.

Tuesday, April 15: 7:00 a.m.-7:00 p.m.

Wednesday-Thursday, April 16-17: 7:30 a.m.-5:00 p.m.

Friday-Saturday, A.pril 18-19: 7:30 a.m.-noon

\section{JOB PLACEMENT CENTER (Hyatt Rickeys Hotel)}

Wednesday-Friday, April 16-18: 9:00 a.m.-5:00 p.m.

\section{PLENARY SESSION (Hyatt Palo Alto Hotel)}

Wednesday, April 17: 6:00 p.m.

Dr. Pieter Meyers,

Director of Conservation Center, Los Angeles County Museum of Art "Materials Studies in the Examination of Works of Art"

\section{POSTER SESSIONS}

Tuesday-Thursday. April 15-17: See locations and times in the Preliminary and Final Programs.

\section{TRANSPORTATION - CONVENTION AIRFARE DISCOUNTS}

American Airlines is offering MRS members exclusive Meeting Saver fares equal to any American Airline special promotional fare for which you may qualify or $35 \%$ discount off day-coach fare, whichever is lower and in effect the date the tickets are purchased. This exclusive Meeting Saver fare waives the Saturday night stay and is valid through the MRS Services desk for roundtrip domestic travel on American Airlines. Tickets may be purchased up to 7 days prior to departure.

\section{RESERVATIONS}

Call the MRS Services desk weekdays 9:00 a.m. to 5:30 p.m. (California time) at one of the telephone numbers listed below. Give the travel specialist the special MRS tile number S-7237. Your reservations on all airlines will be confirmed including connecting and round trip flights and your tickets sent to you directly. The special discount Meeting Saver fare is available for MRS members through a special arrangement with American River Travel in Sacramento, California.

\section{SPECIAL FEATURES}

When you make your flight reservations you can order special diet entrees or any one of seven American Traveler meals. American River Travel specialists will pre-reserve the seat you choose-window, aisle, smoking or nonsmoking and help you confirm car rentals. At the airport, they will issue roundtrip boarding passes so you can skip check-in on your way home.

\section{CALL NOW AND SAVE}

American River Travel

(800) 334-4331 (In Continental U.S.)

(800) 624-4868 (In California)

\section{LOCAL TRANSPORTATION}

Airport shuttle service is available to Hyatt Hotels Palo Alto from San Francisco International Airport (\$12). Exit the terminal and proceed to the middle island with the blue stripe on the concrete terminal. Shuttle service is also available from the San Jose Airport $(\$ 10)$. Arrangements for shuttle service from either airport must be made in advance. You may do so when making airline reservations with American River Travel (numbers listed above) or by calling 1-800-AIRPORT directly. 
Continued from previous page

aging, and new initiatives/novel materials. Invited speakers include: W.G. Klemperer, L. Hench, D. Avnir, K.G. Frase, T.M. Shaw, D.W. Schaefer, K.D. Keefer, J.M. Drake, G.Y. Onoda, L. V. Interrante, R. T Paine, A.R. Cooper, M.C. Weinberg, L.C. Klein, G.L. Messing, S.H. Garofalini, ]. Simmons, G.V. Gibbs, S. Brawer, U. Chowdhry, J. Livage, H. Schmidt, P.E.D. Morgan, and J. Fricke.

\section{Materials for Chemical Sensors}

\section{(Symposium I)}

Wednesday-Thursday, April 16-17

Chairs: S.C. Charg, General Motors Research Laboratory; and J.N. Zemel, University of Pennsylvania.

Approximately 12 papers will cover optical materials, fiber optics, polypyroles, integrated arrays, electrochemical sensors, solid-state gas sensors, dielectrometry, and sensing of environmental toxins.

\section{Frontiers of Materials Research} (Symposium X)

Tuesday. Thursday. April 15.17

Chair: Rustum Roy, Pennsylvania State University.

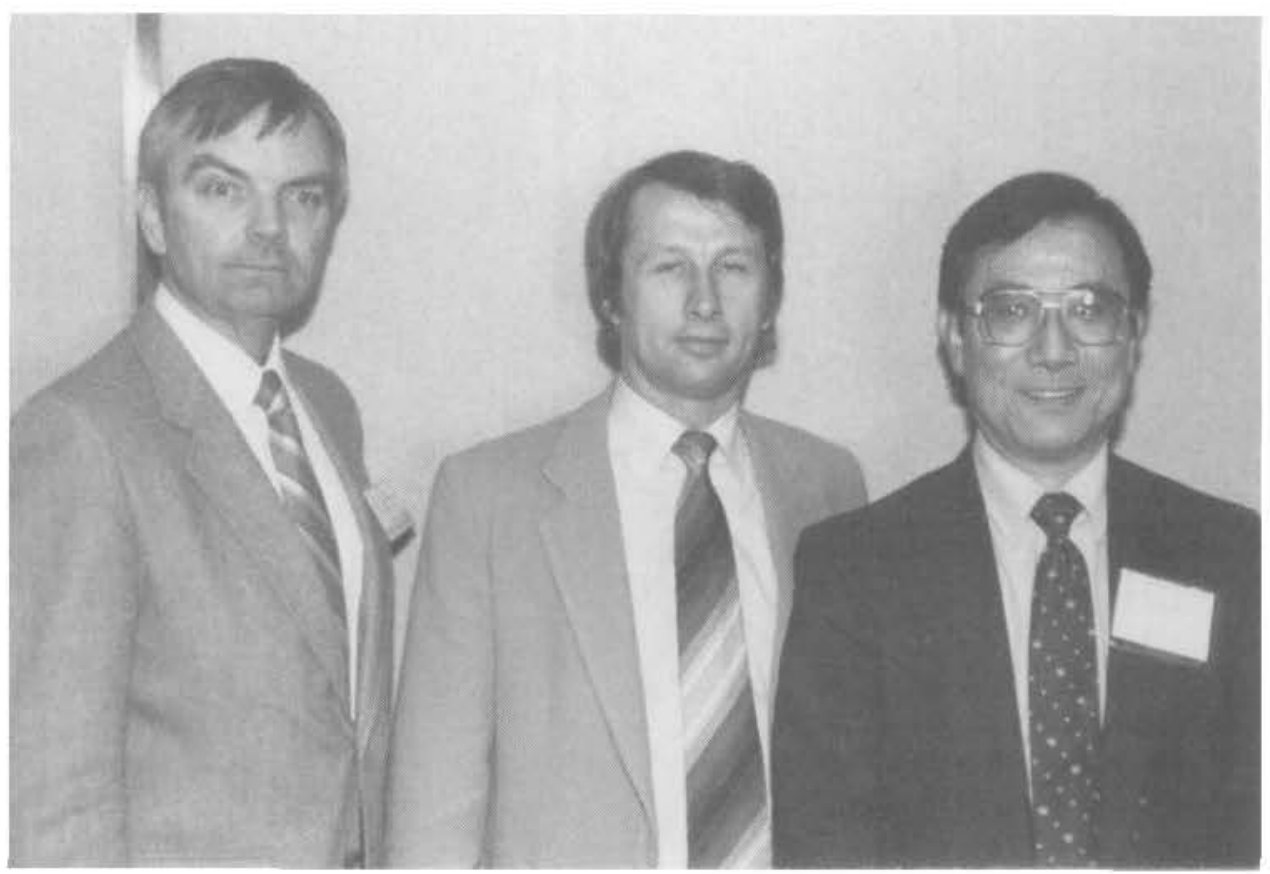

1986 Spring Meeting Program Chairs (left to right): Rod Quinn, Malcolm Thompson, and Wei-Kan Chu.

The speakers will present a tutorial review of recent work in the field, setting it in the context of previous and related science, so that the nonspecialist can obtain a general understanding of the field. Topics will include epitaxial methods for compound semiconductors, fiber-reinforced ceramics, colloids, high-temperature semiconductors, materials for sensors, and amorphous semiconductors.
Milk|S

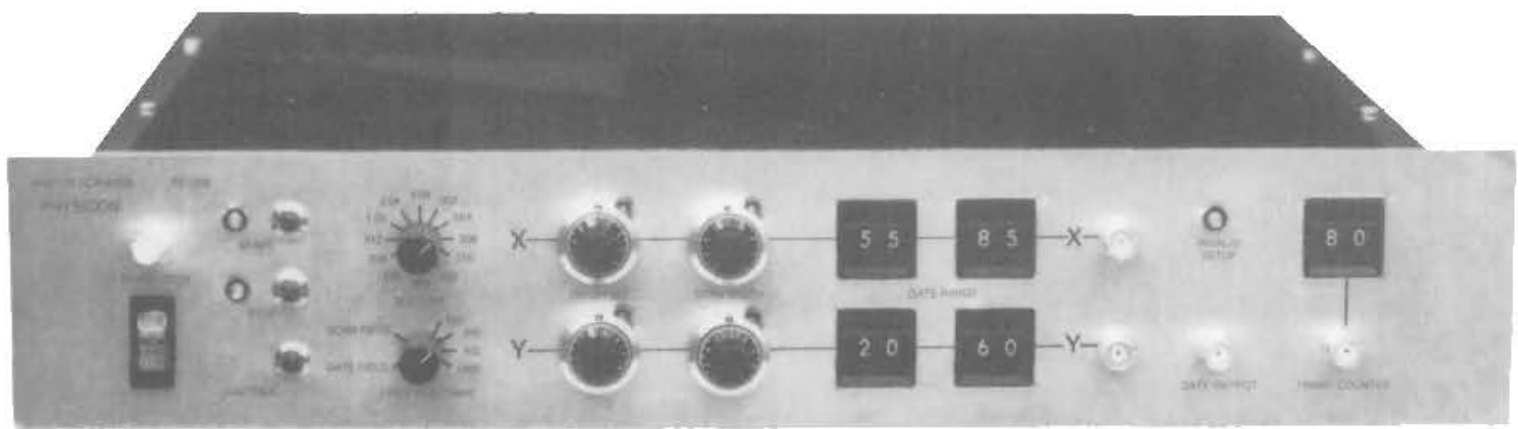

\section{X, Y Raster Scanner RS1200}

for ion and electron beams and Imaging applications.

Bi-directional, high resolution driver circuit, Physicon model AS1200, with -10V to $+10 \mathrm{~V}$ output linear range, capable of precise beam handling $(.01 \%)$ from dc steering to a line scan to full raster scanning within a frame or a part of the trame. Independent controls for scan field, gate fleld, beam sweep from dc to near-video, variable in steps, and 1 to 1000 tines per raster, frame count and search functions. Magnification with zoom feature in combination with plate supply unit RS1221. Date entry port for non-sequential scanning under external control. For use with a dc-coupled X, $Y$ CAT for imaging.

Duoplasmatron Ion source with 2-lens column DPO for SIMS: Intense ion beams of gases with spot size of microns on the target at $5 \mathrm{~cm}$, mass separated. 